\title{
SUMMARY OF RECENT STUDIES OF BEAM-DRIVEN BAE AND CHIRPING MODES IN DIII-D
}

\author{
by \\ W.W. HEIDBRINK,E.M. CAROLIPIO, R.A. JAMES, \\ and E.J. STRAIT
}




\section{DISCLAIMER}

This report was prepared as an account of work sponsored by an agency of the United States Government. Neither the United States Government nor any agency thereof, nor any of their employees, makes any warranty, express or implied, or assumes any legal liability or responsibility for the accuracy, completeness, or usefulness of any information, apparatus, product, or process disclosed, or represents that its use would not infringe privately owned rights. Reference herein to any specific commercial product, process, or service by trade name, trademark, manufacturer, or otherwise, does not necessarily constitute or imply its endorsement, recommendation, or favoring by the United States Government or any agency thereof. The views and opinions of authors expressed herein do not necessarily state or reflect those of the United States Government or any agency thereof. 


\section{DISCLAIMER}

Portions of this document may be illegible in electronic image products. Images are produced from the best available original document. 


\title{
SUMMARY OF RECENT STUDIES OF BEAM-DRIVEN BAE AND CHIRPING MODES IN DIII-D
}

\author{
by \\ W.W. HEIDBRINK, ${ }^{*}$ E.M. CAROLIPIO, ${ }^{*}$ R.A. JAMES, $\dagger$ \\ and E.J. STRAIT
}

This is a preprint of a paper presented at the Fourth International Atomic Energy Agency Technical Committee Meeting, April 25-28, 1995, in Princeton, New Jersey, and published in the PROCEEDINGS

Work supported by

Subcontract No. SC-L134501

of U.S. Department of Energy

Contract Nos. DE-AC03-89ER51114 and W-7405-ENG-48

*University of California at Irvine.

tLawrence Livermore National Laboratory.

GA PROJECT 3466

MAY1995 


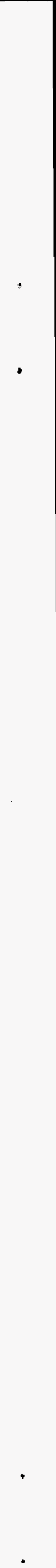




\section{ABSTRACT}

In high beta DIII-D plasmas with intense neutral-beam injection, beta-induced Alfvén eigenmodes (BAE modes) are observed. These instabilities can cause concentrated losses of $>50 \%$ of the fast ions and thus are of concern for future devices. We have now observed BAE modes and resultant fast-ion loss in full-field (2.0 T) discharges where the ratio of parallel velocity to the Alfvén speed is $v_{\|} / v_{A} \simeq 0.3$. In a few discharges, we have also observed a new instability, a "chirping" mode. These modes have frequencies between 50 and $200 \mathrm{kHz}$ that "whistle" down a factor of two in a single $2 \mathrm{~ms}$ burst. They occur in plasmas with relatively large values of fast-ion beta $\left(\left\langle\beta_{f}\right\rangle \gtrsim 1 \%\right)$, Alfvén speed $\left(v_{\|} / v_{A} \lesssim 0.5\right)$, and plasma rotation $\left(f_{\text {rot }}>20 \mathrm{kHz}\right)$. In contrast to the usual Alfvén modes, which are fluid modes of the background plasma, the chirping instabilities seem to be beam modes that are nearly stationary in the plasma frame. 
Collective instabilities driven by energetic alphas may cause anomalous alpha transport, which may degrade the plasma performance or damage internal vacuumvessel hardware in a reactor. In DIII-D, deuterium neutral-beam populations are used to simulate alpha particles. In these simulation experiments, the Alfvén gap structure and ratio of fast-ion speed to Alfvén speed $v_{f} / v_{A}$ are comparable to those anticipated in tokamak reactors, but the velocity distribution of the beam ions is anisotropic (near-tangential injection in the direction of the plasma current is employed) and the ratio of fast-ion gyroradius to plasma minor radius $\rho_{f} / a$ is several times larger than anticipated in ITER.

By the time of the third IAEA technical meeting on alpha particles, both TAE [1] and BAE [2] modes had been observed in DIII-D during intense neutral-beam injection. Following the meeting, papers describing the real frequency [3], stability properties [4], anomalous transport [5], and bursting behavior [6] of TAE modes appeared. In recent work, a new "chirping" instability was observed and BAE modes have been observed to degrade plasma performance in full-field $\left(B_{T}=2.0 \mathrm{~T}\right)$, high poloidal-beta plasmas. This paper briefly summarizes these recent observations. More complete descriptions are currently being prepared [7-9].

Large values of beam beta are needed to drive these instabilities. In Fig. 1, the values of volume-averaged beam beta $\left\langle\beta_{f}\right\rangle$ and $v_{\|} / v_{A}$ for some of the recent observations are compared with earlier TAE and BAE results. Much of the recent work is at higher values of toroidal field (lower values of $v_{\|} / v_{A}$ ). Although only new BAE datum is shown in Fig. 1, BAE modes are found in hundreds of discharges with 


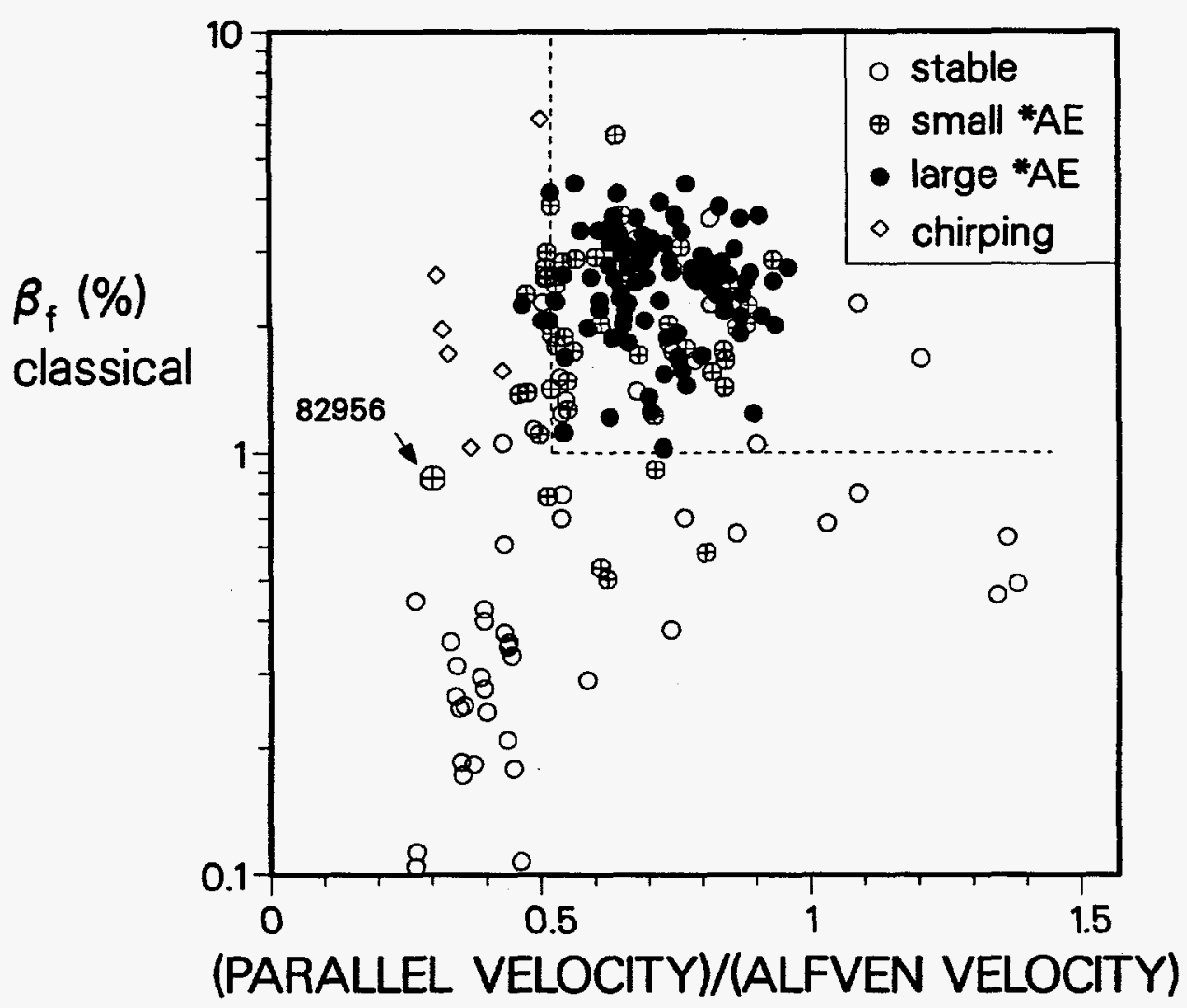

Fig. 1. Relationship of discharges with *AE (TAE or BAE) activity (through the 1992 campaign) [4] to the $2.0 \mathrm{~T}$ discharge with $B A E$ activity (shot 82956 ) and to the discharges with chirping modes. The ordinate represents the classically estimated, volume-averaged beam ion beta $\left\langle\beta_{f c}\right\rangle$. (The actual value may be reduced by fastion losses.) The abscissa represents the ratio of the parallel velocity of full-energy beam ions that ionize on axis $v_{\| 0}$ to the Alfvén speed $v_{A}$ (evaluated using $B_{T}$ and $\left.\bar{n}_{e}\right)$. The dotted lines demarcate the approximate thresholds in $\left\langle\beta_{f c}\right\rangle$ and $v_{\| 0} / v_{A}$ for strong Alfvén activity in DIII-D.

$\left\langle\beta_{f}\right\rangle \gtrsim 1 \%$ for a wide range of values of $v_{\|} / v_{A}[9]$. In contrast, the chirping modes have only been observed in six discharges, all with $v_{\|} / v_{A} \lesssim 0.5$.

BAE modes cause loss of $\gtrsim 50 \%$ of the beam power both in low-field plasmas where $v_{\|} / v_{A} \sim 1[5,10]$ and in high-field plasmas where $v_{\|} / v_{A} \simeq 0.3$ [8]. Chirping modes are also associated with fast-ion loss [7]. 
Figure 2 shows the frequency spectrum measured by magnetic probes in a discharge with $B_{T}=2.0 \mathrm{~T}$. Above $80 \mathrm{kHz}$, the spectrum is characterized by a set of peaks associated with ascending values of toroidal mode number $n$. The qualitative features of the spectrum resemble the TAE [3] and BAE [2] spectra observed in low-field discharges $\left(B_{T} \leq 1.4\right)$. The separation of the peaks is associated with the Doppler shift in these toroidally rotating plasmas [3]. The largest peak corresponds to $n=4$, which is also characteristic of low-field discharges [4].

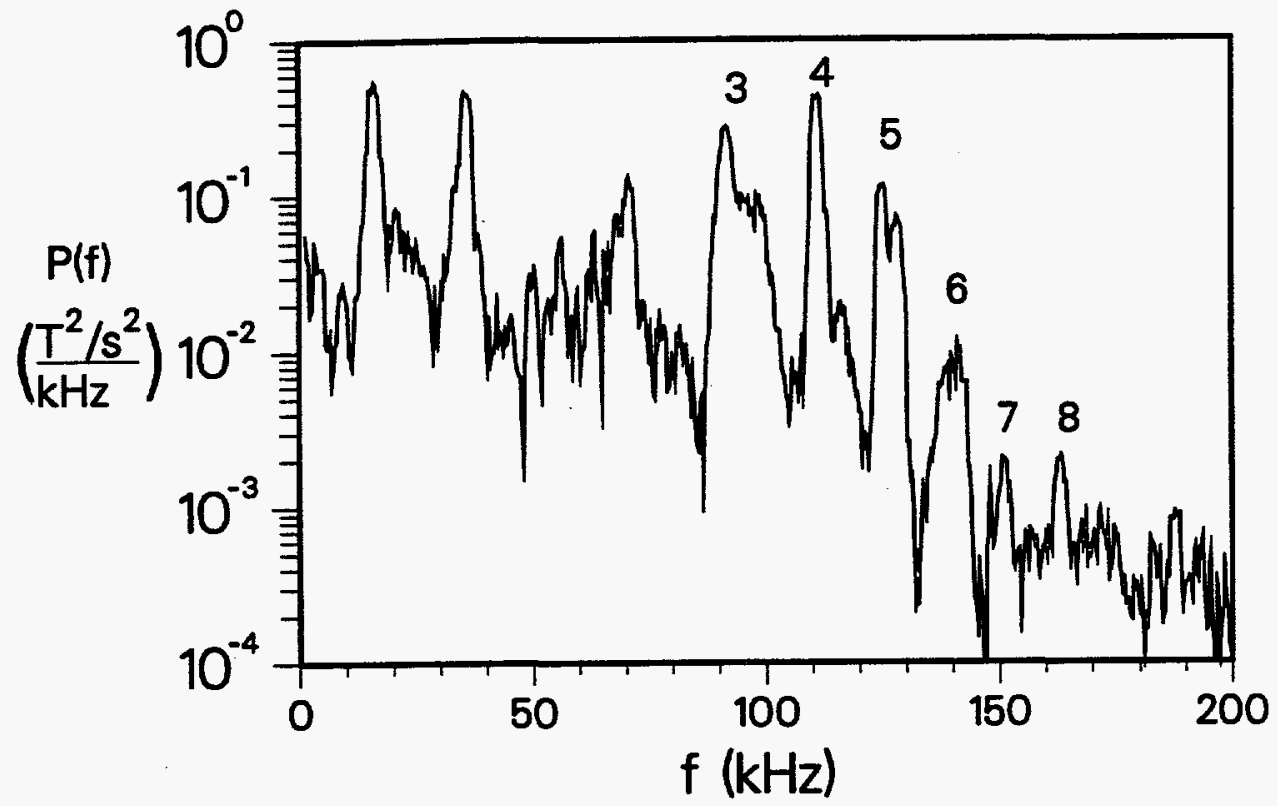

Fig. 2. Cross-power spectrum for two magnetic probes that are separated by $90^{\circ}$ in a high $\beta_{p}$ plasma. The numbers beside each peak represent the toroidal mode numbers obtained from a toroidal array of eight probes. $B_{T}=2.0 \mathrm{~T}$; plasmas current $I_{p}=$ $0.52 \mathrm{MA}_{\text {; }}$ electron density $\bar{n}_{e}=3.3 \times 10^{13} \mathrm{~cm}^{-3}$; beam power $P_{B}=9.7 \mathrm{MW}$; poloidal beta $\beta_{p}=3.6$; double-null divertor configuration.

Previously, it was found that the frequency of BAE modes scales approximately linearly with the Alfvén speed $v_{A}$ [2]. The Doppler-corrected BAE frequency in the 


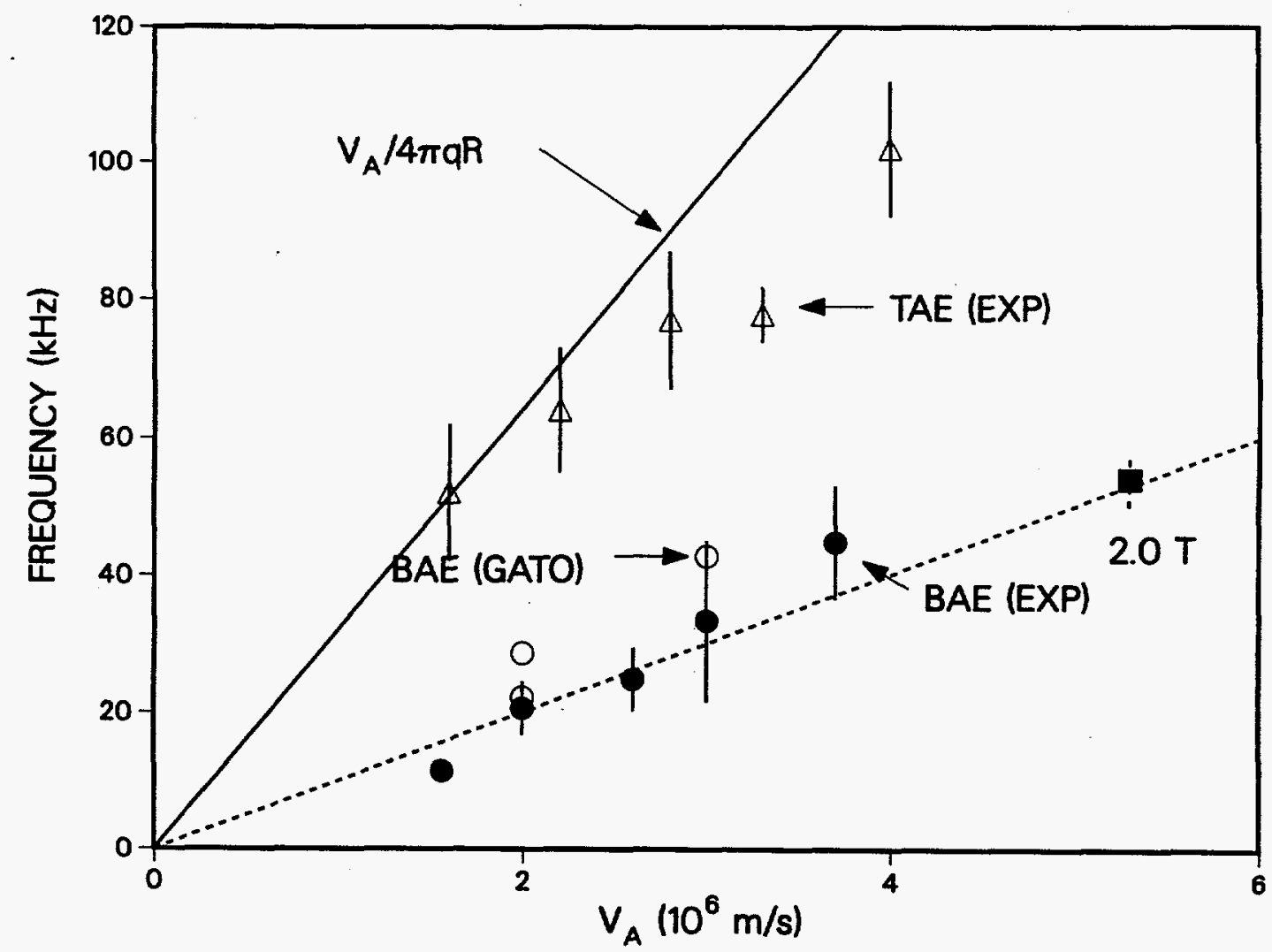

Fig. 3. Doppler-corrected frequency versus the Alfvén speed for the toroidal-field scan data of Ref. [2] and for the discharge shown in Fig. 2 (square). The triangles represent the frequency of the TAE modes observed early in the discharge and the solid circles represent the frequency after the transition to BAE activity. The error bars indicate that standard deviation of the frequency for several busts. Also shown is the nominal TAE frequency (solid line) and the frequencies of BAE modes calculated by an ideal MHD code (open circles).

2.0 T discharge agrees well with the previous scaling (Fig. 3), further confirming that these instabilities are Alfvén modes.

Alfvén modes in DIII-D typically occur in bursts [6]. Within a single burst, any variation of the mode frequency is essentially undetectable $(\gtrsim 0.5 \mathrm{kHz})$. On successive bursts, the mode frequency typically varies a few $\mathrm{kHz}$. In contrast, for chirping modes, the frequency typically varies a factor of two within a single burst. Figure 4 shows the frequency spectrum for a chirping mode. The broad spectrum is caused by the 


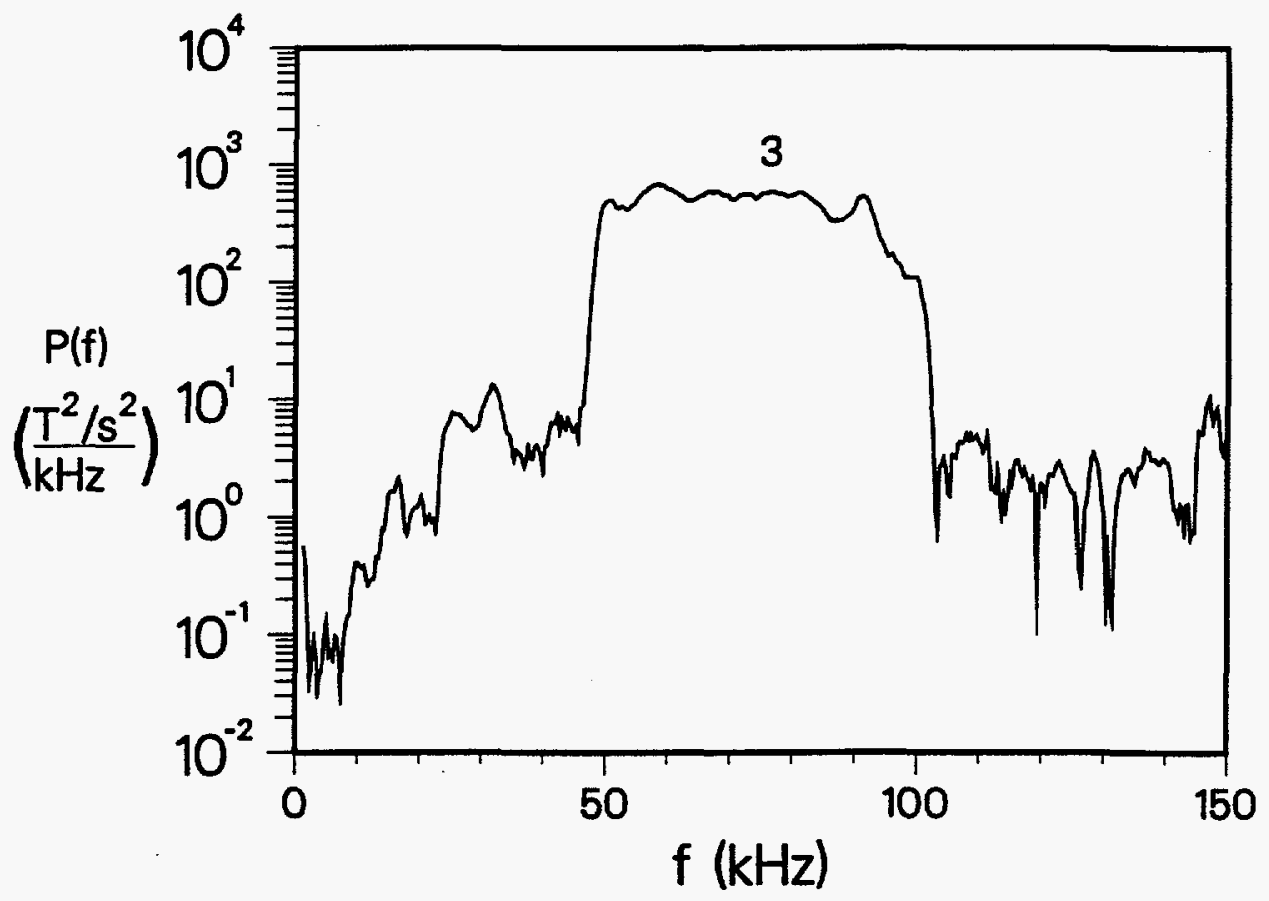

Fig. 4. Cross-power spectrum for two magnetic probes that are separated by $90^{\circ}$ during a 2 ms burst of chirping activity. The instability has toroidal mode number $n=3$. $B_{T}=1.7 \mathrm{~T} ; I_{p}=0.62 \mathrm{MA} ; \bar{n}_{e}=2.5 \times 10^{13} \mathrm{~cm}^{-3} ; P_{b}=12.2 \mathrm{MW} ; T_{e}(0)=$ $3.1 \mathrm{keV}$; double-null divertor configuration.

rapid temporal variation of the frequency during the burst [7]. The toroidal mode number ( $n=3$ in this case) remains constant throughout the burst, however.

The chirping modes occur in plasmas with relatively high values of toroidal - rotation $\left(f_{\text {rot }}>20 \mathrm{kHz}\right)$. Apparently, the large value of $f_{\text {rot }}$ accommodates a mode that is stationary in the plasma frame $\left(f_{\text {plasma }} \simeq f_{\text {lab }}-n f_{\text {rot }} \simeq 0\right)$ yet can still resonate with the circulating beam-ion population $\left(f_{\text {lab }} \simeq n f_{\text {rot }} \sim f_{\text {circ }}\right)$. In contrast, for BAE modes the Doppler shift is smaller so that $f_{\text {plasma }}>0$ when $f_{\text {lab }} \sim f_{\text {circ }}$. It has been proposed that these chirping modes are a type of beam mode in which the bulk plasma rotation plays an important role [7].

In summary, beam-driven, intermediate- $n$ instabilities with laboratory frequencies of $O(100 \mathrm{kHz})$ are observed in DIII-D: the BAE and a chirping instability. 
Alpha-driven chirping modes are not anticipated in a reactor, but their observation helps clarify the distinction [11] between beam modes and fluid modes. On the other hand, alpha-driven BAE modes are potentially dangerous in future devices, particularly tokamak reactors that operate at large values of poloidal beta. 


\section{REFERENCES}

[1] HEIDBRINK, W.W., STRAIT, E.J., DOYLE, E.J., SAGER, G., and SNIDER, R.T., Nucl. Fusion 31 (1991) 1635.

[2] HEIDBRINK, W.W., STRAIT, E.J., CHU, M.S., and TURNBULL, A.D., Phys. Rev. Lett. 71 (1993) 855.

[3] STRAIT, E.J., HEIDBRINK, W.W., and TURNBULL, A.D., Phys. Contr. Fusion 36 (1993) 1211.

[4] STRAIT, E.J., HEIDBRINK, W.W., TURNBULL, A.D., CHU, M.S., and DUONG, H.H., Nucl. Fusion 33 (1993) 1849.

[5] DUONG, H.H., HEIDBRINK, W.W., STRAIT, E.J., et al., Nucl. Fusion 33 (1993) 749.

[6] HEIDBRINK, W.W., and DANIELSON, J.R., Phys. Plasma 1 (1994) 4120.

[7] HEIDBRINK, W.W., "Beam-Driven Chirping Instability in DIII-D," submitted to Plasma Phys. Contr. Fusion (1995).

[8] JAMES, R.A., et al., "Fast-Ion Confinement During High $\beta_{p}$ Operation in DIII-D," to be submitted to Nucl. Fusion (1995).

[9] HEIDBRINK, W.W., etal., "BAE Modes in DIII-D," in preparation (1995).

[10] HEIDBRINK, W.W., in Theory of Fusion Plasmas (Proc. Joint Varenna-Lausanne Workshop 1994), p. 49, Bologna, 1994, Editrice Compositori (ISBN 88-7794-066-2).

[11] TSAI, S.-T., and CHEN, L., Phys. Fluids B 5 (1993) 3284. 


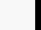




\section{ACKNOWLEDGMENT}

The contributions of the DIII-D team are gratefully acknowledged. This work was supported by Subcontract No. SC-L134501 of U.S. Department of Energy Contract Nos. DE-AC03-89ER51114 and W-7405-ENG-48. 